\title{
A System Compensation Based Model Predictive AGC Method for Multiarea Interconnected Power Systems with High Penetration of PV System and Random Time Delay between Different Areas
}

\author{
Xilin Zhao $\mathbb{D}$, Jingjing He, Bo Fu $\mathbb{D}^{\mathbb{D}}$, Li He, and Guanghui Xu \\ Hubei Key Laboratory for High-Efficiency Utilization of Solar Energy and Operation Control of Energy Storage System, \\ Hubei University of Technology, Wuhan 430068, China \\ Correspondence should be addressed to Xilin Zhao; zhaoxl@mail.hbut.edu.cn and Bo Fu; fubofanxx@mail.hbut.edu.cn
}

Received 4 September 2018; Accepted 9 October 2018; Published 22 October 2018

Academic Editor: José Domingo Álvarez

Copyright (C) 2018 Xilin Zhao et al. This is an open access article distributed under the Creative Commons Attribution License, which permits unrestricted use, distribution, and reproduction in any medium, provided the original work is properly cited.

\begin{abstract}
In order to mitigate the negative influence of geographical dispersity of modern power system and the penetration of renewable energy, a system compensation based model predictive AGC method is proposed in this paper. A compensation unit is introduced in AGC system to reduce the influence of PV power output fluctuation. Furthermore, because the distributed power system is geographically dispersed, which leads to some defects such as time delay and packet dropouts, a selection and optimization algorithm is presented to obtain the appropriate variable when delays exist. Finally, a two-area interconnected power grid with PV systems is shown as an example to testify the feasibility and effectiveness of the proposed method. The simulation results indicate that the system controlled by the proposed method has the expected dynamic performance.
\end{abstract}

\section{Introduction}

Automatic Generation Control (AGC) is designed to minimize frequency deviations and to maintain the system frequency close to its scheduled value when there is a load and resource variation in power systems [1-3]. As an important research field in power system operation and control, AGC technique is developed both practically necessary and theoretically interesting. Therefore, many AGC strategies have been proposed as in numerous references, for example, proportional integral differential (PID) [4-6], sliding mode control (SMC) [7], self-adaptive control [8], and robust control [9].

At present, due to the large scale of power grid and the high penetration of renewable energy, research on the AGC is more challenging. On the one hand, large scale power system leads to the distributed feature of multiarea interconnected power systems which yield synchronous problem during control process of each subsystem. On the other hand, majority renewable energy outputs such as photovoltaic, wind generation usually tend to be uncertain because of natural and meteorological conditions. Thus, many of the research on AGC for modern power system focus on two major aspects: first, control strategy for power grid of large scale; second, the control approach for AGC in the presence of renewable energy.

The presence of renewable energy will lead to the complexity of AGC implementation due to the impact of external environment. This issue also raises concern on the modeling of renewable energy system under AGC [10]. Thus, some AGC methods have been researched according to the building of the model of hybrid energy system. Xu et al. [11] proposed a dynamic gain-tuning control (DGTC) method for AGC with effects of wind resources, of which the PI control parameters can be automatically and dynamically calculated according to different disturbances in a power system. Basit et al. [12] described an algorithm to control the active power balance through automatic generation control process with wind power integration of large scale. Rahman et al. [13] proposed an optimal-based PID controller for AGC of a two-area hybrid thermal system with solar and wind turbine. Obviously, the power output of most renewable 
energy resources is affected by the environment. In order to improve the efficiency of energy conversion, the maximum power point tracking (MPPT) technique is indispensable. But the aforementioned references did not discuss the problem about the influence of renewable power output on AGC when MPPT strategy is carried out.

Since large scale power grid is geographically dispersed and is an interconnected system with distributed generators, traditional centralized controllers are difficult to acquire the expected control performance. Mi et al. [7] discussed a decentralized sliding mode control method for AGC of multiarea power systems with uncertainties. Mohamed et al. [14] presented a MPC based decentralized control mode for AGC in an interconnected power system. However, the decentralized control mode does not suit for the coordination of each subsystem because there is no information interaction between them. Thus, Pan et al. [15] researched fractional order PID controller for distributed AGC to solve the problem caused by the uncertainty of the distributed energy system. Apostolopoulou et al. [16] presented an adaptive AGC scheme based on a dynamic model of balancing authority area. Arya et al. [17] illustrated a novel fractional order PID controller for three structures of multiarea multisource AGC system. The distributed control mode can solve the problem of information interaction preferably. However, an important problem is that a majority of current researches ignored the time delay between different subsystems. Due to the geographically dispersion of each subsystem, the time delay exists objectively during the information interaction between different subsystems. Therefore, it needs to be taken into consideration during AGC process, especially for networked AGC system due to the introduction of smart grid. In fact, some scholars [18-20] discussed the influence of time delay in AGC system. But in these references, the time delay was considered as the system constraint, which makes the analyses of delays characteristics not sufficient.

Essentially, the negative impact of time delay on AGC system resulting from its existence will cause the missing of sampling data at corresponding sampling instant. Thus, the key point of the control strategy under the existence of time delay is how to deal with the missing data. Model predictive control (MPC) is a popular control method for its ability to handle multivariable, constrained systems [21, 22]. In a typical MPC scheme, a sequence of optimal control (or state) variables is obtained based on the prediction of the system behavior over a finite time horizon at each sampling interval, but only the first element is applied to the system. The predictive control (or state) variables in the obtained sequence represent the optimal tendency of subsequent sampling instant under current information. If the sampling information is not received by the controller in time, the lost information can be estimated by the predictive value of previous sampling instant. Additionally, MPC is also an effective method for AGC due to its favorable characteristics [23-25]. Therefore, a MPC based distributed AGC method is discussed in this paper for multiarea interconnected power systems with random time delay existing between different regions, together with high penetration of photovoltaic system.
An improved AGC method is proposed to maintain the frequency of the power system close to its scheduled value for multiarea interconnected power systems with high penetration of PV system and random time delay between different areas in this paper. Firstly, multiarea power system model is built with high penetration of photovoltaic (PV) system and time delay existing between different areas. Then, the photovoltaic characteristic of PV cell is discussed. A compensation unit is introduced in AGC system to reduce the influence of PV power output fluctuation. Furthermore, because the time delay will cause the loss of sampling data, a selection and optimization algorithm is presented to obtain the appropriate variable when delays exist.

This paper is organized as follows. After introducing the background of the research, the PV system model and the model configurations of two-area interconnected AGC system with random time delay are analyzed in Section 2. In Section 3, discretization process and the influence analysis of the time delay between different regions is presented. In Section 4, principle of MPC and the system compensation are analyzed. In order to obtain the appropriate control variable when time delay exists, the obtainment of absent signal is described. In Section 5, a numerical example is provided, which illustrates the effectiveness of the proposed method. Finally, a conclusion is provided in Section 6.

\section{Distributed AGC System Model}

2.1. Photovoltaic System Model. The conflict between environmental pollution and social development yields the extensive application of renewable energy. The presence of renewable energy in power grid, namely, hybrid power system, renders the AGC process more complex. For example, when PV system is included in a power grid, the power output variation of the PV system will affect the balance between load and resource of the power system. However, the power output variation of the PV system is unavoidable for the environmental uncertainty. The uncertainty leads to the emergence of research on the MPPT, the purpose of which is to pursue the maximum power output. Thereby, the power output characteristic of PV array needs to be discussed before the research on AGC.

The PV array is assembled by PV cells according to the voltage and power demand. A PV cell is a semiconductor device which can absorb energy of sunlight and convert it into electric energy through photoelectric effect. The typical equivalent circuit of PV cell is shown in Figure 1.

The output characteristic of PV cell is given as [26]

$$
\begin{aligned}
i_{P V} & =i_{p h}-i_{D}-i_{s h} \\
& =i_{p h}-i_{o}\left(e^{q\left(v_{p v}+i_{P V} R_{s}\right) / A K T}-1\right)-\frac{v_{p v}+i_{P V} R_{s}}{R_{s h}},
\end{aligned}
$$

where $i_{\mathrm{PV}}$ and $v_{\mathrm{PV}}$ are the output current and voltage, respectively, $i_{\mathrm{ph}}$ is the photocurrent, $i_{\mathrm{D}}$ is the diode junction current, $i_{\mathrm{o}}$ is the reverse saturation current, $q$ is the electronic charge, $K$ is the Boltzmann constant, $T$ is the PV cell temperature, $A$ is the diode factor, and $R_{\mathrm{s}}$ and $R_{\mathrm{sh}}$ are the PV cell series and parallel resistance, respectively. 


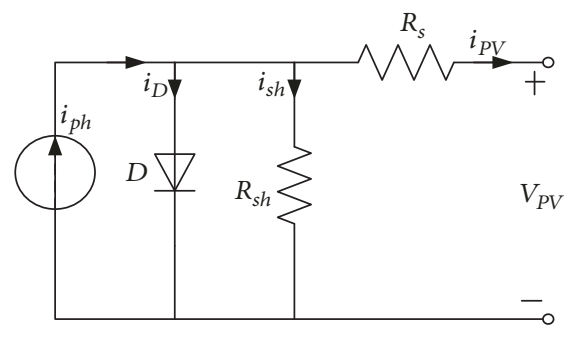

FIGURE 1: Equivalent model of PV cell.

Then, the power output is given by

$$
P_{P V}=v_{P V} i_{P V}
$$

2.2. AGC System Model Building. A large power system is usually divided into several subsystems which are connected by the tie-lines for efficient operation and control. The subsystems represent interconnected regional power grid. Without loss of generality, a two-area interconnected power system with penetration of PV system and time delay between different areas is considered as an example for design and analysis purposes. The system model is shown in Figure 2.

The time delay is represented by $\tau_{1}, \tau_{2}, \tau_{11}, \tau_{12}, \tau_{21}, \tau_{22}$, where $\tau_{1}, \tau_{2}$ represent controller-to-actuator (C-A) delay and $\tau 11, \tau_{12}, \tau_{21}, \tau_{22}$ represent sensor-to-controller (S-C) delays, respectively. The difference of $\mathrm{S}-\mathrm{C}$ delays indicates that the time delays between different areas are not the same. In the model, $T_{\mathrm{g} i}$ is the time constant of the governor for area $i ; T_{\mathrm{t} i}$ is the time constant of the generator for area $i ; K_{\mathrm{r} i}$ is the reheat coefficient of the steam turbine for area $\mathrm{i}$; Tri is the reheat time constant for area $i ; R_{i}$ is the speed regulation parameter for area $i ; B_{i}$ is the frequency bias factor for area $i ; M_{i}$ is the rotary inertia of assembling unit for area $i ; D_{i}$ is the damping coefficient of load for area $i ; \Delta P_{\mathrm{t} i}$ is the change in turbine output for area i; $\Delta P_{r i}$ is the change in thermal power output of reheat steam turbine generator sets for area $i ; \Delta X_{\mathrm{g} i}$ is the change in valve position of the governor for area $i ; \Delta P_{c i}$ is the control variable of controller for area $i ; \Delta P_{\mathrm{L} i}$ is the load changes for area $i ; \Delta f_{i}$ is the frequency deviation for area $i$; $\Delta P_{\mathrm{t} 12}$ is the tie-line power flow for area $i ; T_{12}$ is the power system synchronizing coefficient; $A C E_{i}$ is the area control error for area $i$; is the light intensity; $P_{\mathrm{DSE}}$ is the PV power output.

The transfer function of each component is also described in Figure 2. The relationship between different signals is given by

$$
\begin{aligned}
A C E_{i} & =(-1)^{i+1} \Delta P_{t 12}+B_{i} \Delta f_{i} \quad(i=1,2) \\
\Delta P_{c i} & =u_{i} e^{-\tau_{i} s} \quad(i=1,2) \\
\Delta X_{g i} & =\frac{R_{i} \Delta P_{c i}-\Delta f_{i}}{R_{i}\left(1+s T_{g i}\right)} \quad(i=1,2) \\
\Delta P_{t i} & =\frac{1+s K_{r i} T_{r i}}{\left(1+s T_{t i}\right)\left(1+s T_{r i}\right)} \Delta X_{g i} \quad(i=1,2)
\end{aligned}
$$

$$
\begin{aligned}
& \Delta f_{1}=\frac{s\left(\Delta P_{t 1}+P_{D S E}-\Delta P_{L 1}\right)+2 \pi T_{12} \Delta f_{2} e^{-\tau_{21} s}}{s\left(D_{1}+s M_{1}\right)+2 \pi T_{12} e^{-\tau_{11} s}} \\
& \Delta f_{2}=\frac{s\left(\Delta P_{t 2}+P_{D S E}-\Delta P_{L 2}\right)+2 \pi T_{12} \Delta f_{1} e^{-\tau_{12} s}}{s\left(D_{2}+s M_{2}\right)+2 \pi T_{12} e^{-\tau_{22} s}}
\end{aligned}
$$

where $u_{i}$ is the output of MPC controller.

Owing to the physical and mechanical limitations, the generation rate constraint (GRC) of $3 \%$ per minute and deadband of $\pm 0.036 \mathrm{~Hz}$ is considered in this paper. For optimizing purpose, the objective function is determined by

$$
\begin{aligned}
\min & \boldsymbol{J}_{A G C} \\
= & \left(\boldsymbol{R}_{S}-A C E\right)^{T}\left(\boldsymbol{R}_{S}-A C E\right) \\
& +\left(f_{S}-\Delta \boldsymbol{f}\right)^{T}\left(f_{S}-\Delta f\right)+U^{T} R \boldsymbol{U}
\end{aligned}
$$

where $R_{\mathrm{S}}$ is the expected output of $A C E$ and $f_{\mathrm{S}}$ is the expected output of $\Delta f$.

\section{Analysis and Processing of Time Delay}

3.1. Discretization of Time Delay. As a random signal, time delay needs to be discretized in a discrete system first. Due to the existence of the sampling period, when time delay is less than the sampling period, it will have no impact on the control effect. Otherwise, the control performance will be affected. According to the sampling period and the value of the delay at sampling instant, the random delay signal can be converted to a time series, which is characterized as a random Markov jump process [27]. As an example, the discretization process of a delay signal is shown in Figure 3.

3.2. Influence Analysis of Time Delay. When time delay exists between different areas which represent different subsystems, the AGC effect of each subsystem is different. In terms of the cases about with or without time delay, the output response of aforementioned AGC system can be obtained as shown in Figure 4, where the controller is designed based on MPC theory and the load changes of the two-area are assumed to be step perturbation with 0.04 and $0.01 \mathrm{pu}$ amplitude, respectively.

The output responses indicate that the control performance of AGC system will deteriorate when the channel delay exists. Therefore, in order to achieve the expected control performance, the influence of the channel delay cannot be ignored.

\section{Design of the Control Approach for AGC System}

4.1. Background of Model Predictive Controller. MPC is widely recognized as a favorite technique for this model based control strategy uses a predicted sequence of system response to establish an appropriate control response by minimizing an objective function. It also can be an effective method for AGC 


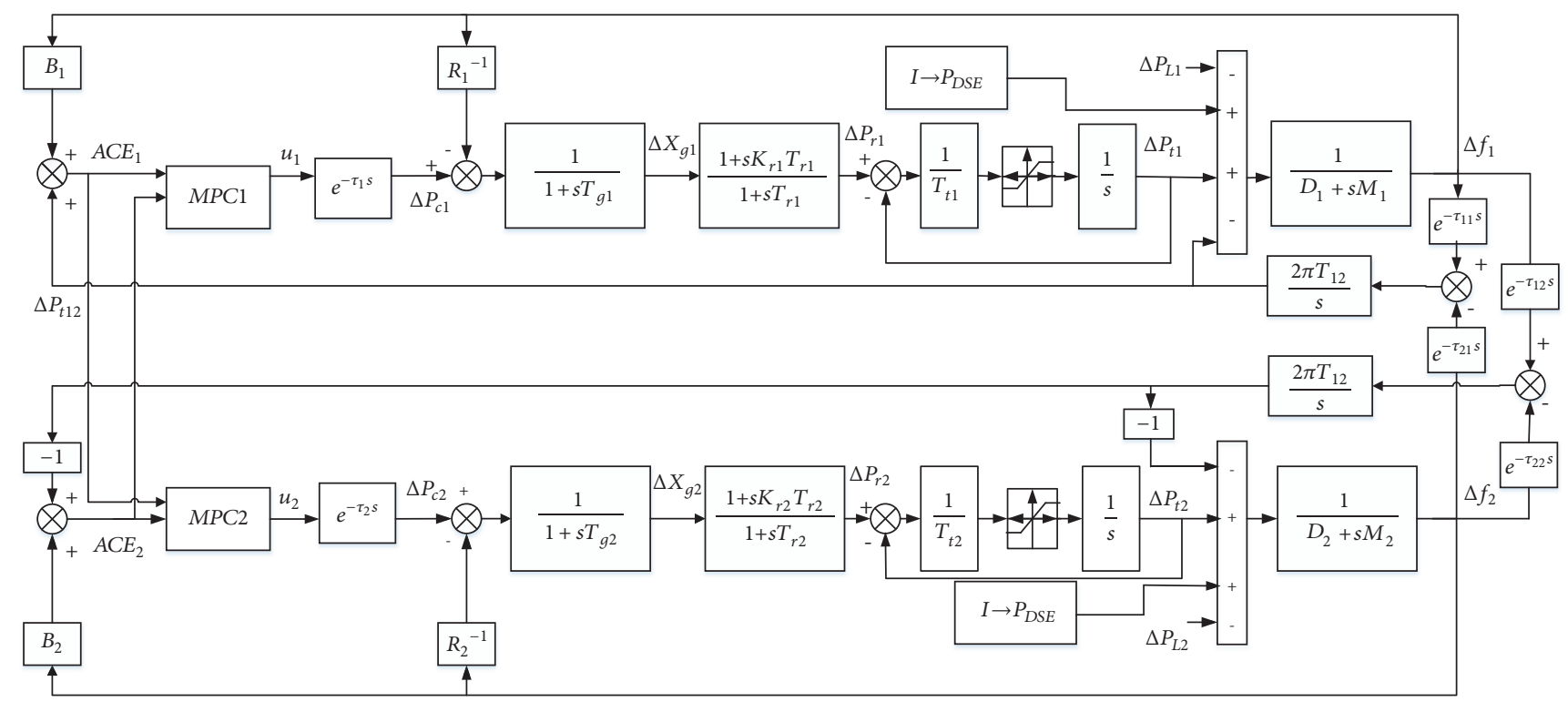

FIgURE 2: Two-area interconnected power grid AGC dynamic model with time delay.

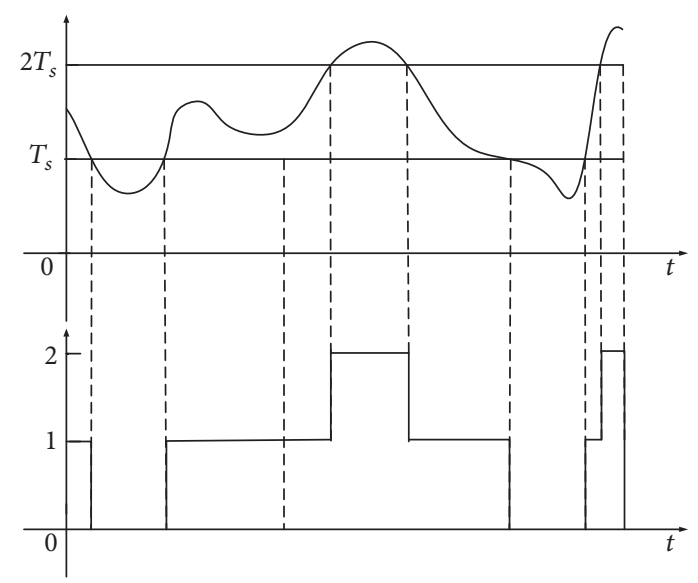

FIGURE 3: Discretization process of time delay.

due to its characteristics. Consider the following discretetime system:

$$
\begin{aligned}
x(k+1) & =\boldsymbol{A} x(k)+\boldsymbol{B} u(k) \\
y(k) & =\boldsymbol{C} x(k),
\end{aligned}
$$

subject to

$$
\begin{aligned}
& u_{\min }=u(k) \leq u_{\max } \\
& y_{\min } \leq y(k) \leq y_{\max },
\end{aligned}
$$

where $x \in R^{n}, u \in R^{m}$, and $y \in R^{s}$ are the state, input, and output variables with correspond dimension, respectively.

Generally, the objective function is designed as a quadratic function about the deviation between expected value and predicted value of the system response. The control object is to minimize the objective function which can be written as follows:

$$
J=\left(\boldsymbol{R}_{S}-\boldsymbol{Y}\right)^{T}\left(\boldsymbol{R}_{S}-\boldsymbol{Y}\right),
$$

where $R_{\mathrm{s}}$ is the expected output of the system and $Y$ is the output sequence in prediction horizon.

At each sampling instant, the optimization problem is solved to obtain the optimal control sequence as

$$
\boldsymbol{U}^{*}=\left[\begin{array}{llll}
u^{*}(k) & u^{*}(k+1) & \cdots & u^{*}\left(k+N_{c}-1\right)
\end{array}\right]^{T},
$$

where $N_{c}$ is the control horizon and $k$ is the sampling time instant. Only the first element in the control sequence is carried out to the system during the control process.

Corresponding to the optimal control sequence, the predictive sequence of state variables and output can respectively be obtained as

$\boldsymbol{X}$

$$
\begin{aligned}
& =\left[\begin{array}{lllll}
X\left(k_{i}+1 \mid k_{i}\right) & X\left(k_{i}+2 \mid k_{i}\right) & \cdots & X\left(k_{i}+N_{P} \mid k_{i}\right)
\end{array}\right]^{T}, \\
& \boldsymbol{Y} \\
& =\left[\begin{array}{lllll}
Y\left(k_{i}+1 \mid k_{i}\right) & Y\left(k_{i}+2 \mid k_{i}\right) & \cdots & Y\left(k_{i}+N_{P} \mid k_{i}\right)
\end{array}\right]^{T},
\end{aligned}
$$

where $N_{\mathrm{P}}$ is the prediction horizon.

4.2. System Compensation Strategy. Conventionally, when traditional MPC is applied separately, it is mainly applicable in the process of slow dynamic changes in the larger sampling period, which involves a large amount of computation and time consuming. Therefore, considering the introduction of cascade compensation unit can enhance the system stability and performance, it is necessary to add a unit to the original system. The compensation unit is designed as

$$
G_{\mathrm{c}}(s)=\frac{m s+n}{s+q} .
$$



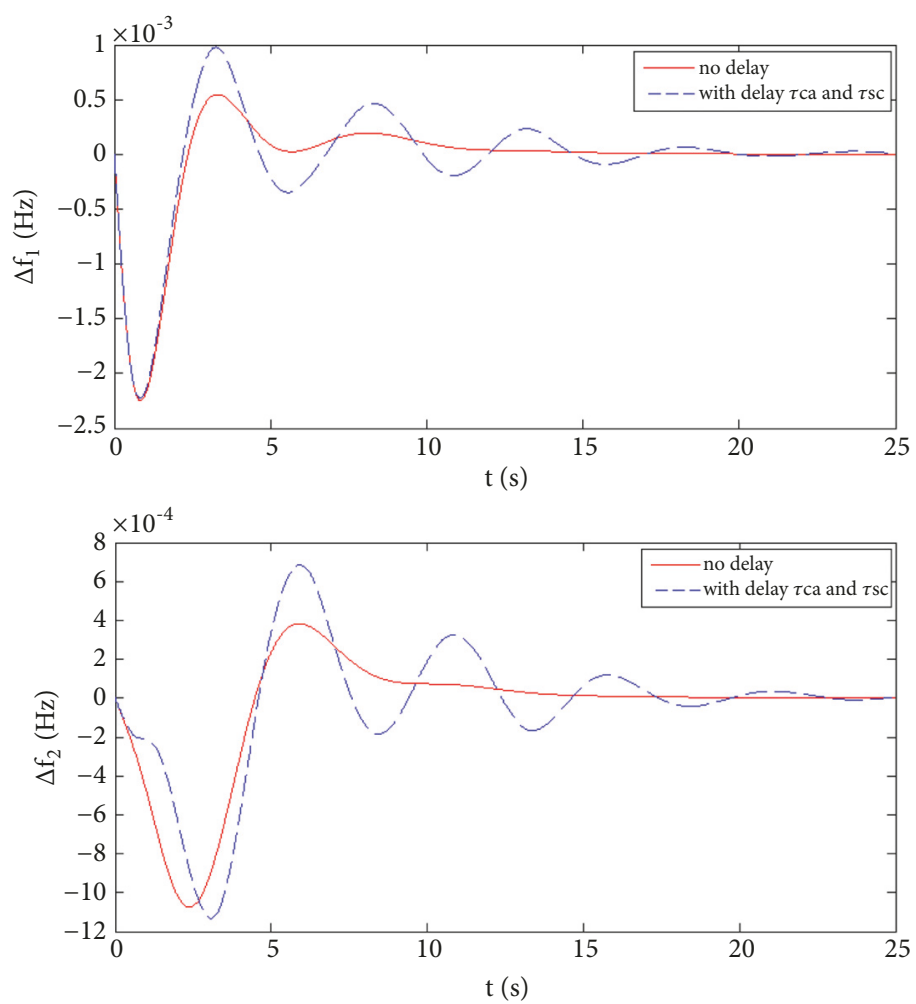

FIGURE 4: Response curve comparison of $\Delta \mathrm{f}$ with or without delay. (a) Response curve of $\Delta f_{1}$. (b) Response curve of $\Delta f_{2}$.

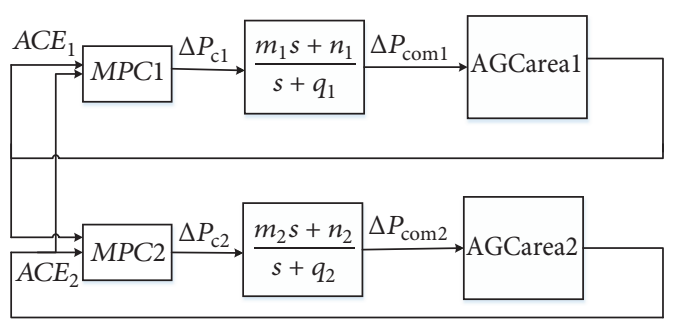

FIGURE 5: System block diagram after compensation.

The design mode possess diversity, in the case of $q=0, G_{c}(s)$ is equivalent to a PI controller; when $q=0$ and $n=0, G_{c}(s)$ is equivalent to a proportional link.

In order to pursue the best control effect, the particle swarm optimization (PSO) is applied to obtain the optimal solution of the parameters of the compensation unit, so as to avoid or reduce the influence of the photovoltaic power uncertainty on the AGC.

The way to compensate for the system is shown in Figure 5.

As shown in Figure 5, the compensation unit is added between the controller and the actuator to achieve compensation for the controller. The compensation unit includes six parameters $m_{1}, n_{1}, q_{1}, m_{2}, n_{2}, q_{2}$ which is optimized through particle swarm optimization (PSO) for global optimization.

$$
\begin{gathered}
\dot{X}_{i}(t)=A_{i i} X_{i}(t)+A_{\tau 1} X_{i}\left(t-\tau_{i i}\right)+B_{i i} U\left(t-\tau_{i}\right) \\
+F_{i i} W_{i}(t)+\sum_{i \neq j}\left(A_{i j} X_{j}(t)+A_{\tau 2} X_{j}\left(t-\tau_{i j}\right)\right.
\end{gathered}
$$

$$
\begin{aligned}
& \left.+B_{i j} U_{j}(t)+F_{i j} W_{j}(t)\right) \\
& Y_{i}(t)=C_{i i} X_{i}(t)+C_{\tau 1} X_{i}\left(t-\tau_{i i}\right)+C_{\tau 2} X_{i}\left(t-\tau_{i j}\right) \\
& \quad(i=1,2 ; j=1,2)
\end{aligned}
$$

in which

$$
\begin{aligned}
& X_{i}=\left[\begin{array}{lllll}
\Delta f_{i} & \Delta P_{\mathrm{t} i} & \Delta P_{\mathrm{ri}} & \Delta X_{\mathrm{g} i} & \Delta P_{\mathrm{t} 12}
\end{array}\right]^{T} \\
& U_{i}=\left[\Delta P_{c i}\right] \\
& W_{i}=\left[\Delta P_{\mathrm{Li}}\right] \\
& Y_{i}=\left[\begin{array}{lll}
A C E_{i} & \Delta f_{i} & \Delta P_{\mathrm{t} 12}
\end{array}\right]^{T}
\end{aligned}
$$

After compensation, the system state variables, control variables, disturbance variables, and output variables are as below, respectively,

$$
\begin{aligned}
& X_{i}=\left[\begin{array}{llllll}
\Delta f_{i} & \Delta P_{\mathrm{t} i} & \Delta P_{\mathrm{r} i} & \Delta X_{\mathrm{g} i} & \Delta P_{\mathrm{t} 12} & \Delta P_{\mathrm{com} i}
\end{array}\right]^{T} U_{i} \\
& =\left[\Delta P_{c i}\right] \\
& W_{i}=\left[\Delta P_{\mathrm{L} i}\right] \\
& Y_{i}=\left[\begin{array}{lll}
A C E_{i} & \Delta f_{i} & \Delta P_{\mathrm{t} 12}
\end{array}\right]^{T}
\end{aligned}
$$

where $X_{j} \in R^{n}, U_{j} \in R^{m}, W_{j} \in R^{k}$, and $Y_{j} \in R^{r}$ represent the state variables, control variables, disturbance variables, 


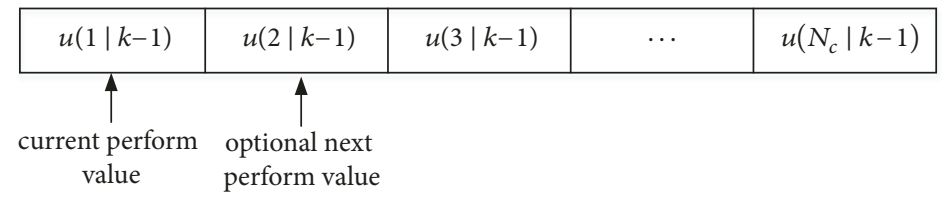

FIGURE 6: Schematic diagram of control variables selection.

and output variables of the $j$ th region system adjacent to the $i$ th region, respectively. Then, the associated matrixes of the state equation of the system are described in supplementary material available here.

4.3. Obtainment of Control Variables. The time delay between different areas causes the loss of control information. In order to guarantee the AGC performance, the lost information needs to be supplemented. To fulfill the supplement purpose, a buffer is used to store the latest data that has the most recent time stamp. According to the latest data and the predictive characteristic of MPC, the influence caused by the lost information can be compensated. The processing procedure is indicated in Figure 6. For example, information with time stamp $k-1$ is the most recent data and is stored in the buffer. The control sequence at sampling instant $k-1$ is obtained and the first element in the sequence is applied to the system as the control variable. Suppose the information at sampling instant $k$ is absent for the time delay. Then, the control variable cannot be obtained for the lost data. Because the second element $u(2 \mid k-1)$ in control sequence obtained by the data with time stamp $k-1$ is the predictive control variable of sampling instant $k$, the predictive value can be chosen as the actual control variable at sampling instant $k$. If the data at sampling instant $k+1$ is also lost, then, the third element $u(3 \mid k-1)$ in control sequence can be chosen as the actual control variable and so on.

Generally, a reasonable predictive control signal can be obtained to replace the absent control signal. However, it is possible that the control effect caused by the first element in the control sequence, recalculated according to the received latest data, is better than that of the above method during some certain control modes. Therefore, in the process of realization, the actual control signal is optimal selected between the corresponding element and the first element in the recalculated control sequence.

\section{Numerical Example}

In this paper, the studied system is simulated based on Matlab/Simulink. The construction of the system covers the random delay between different areas. The controller is realized by means of MPC toolbox, and the prediction horizon $N_{\mathrm{P}}$ is set to 10; control horizon $N_{\mathrm{c}}$ is set to5. Sampling period is set to $0.01 \mathrm{~s}$. Time delay is exerted through a random sequence to simulate. Detailed parameters are shown in Table 1 . The optimal parameters of the compensation unit for step and random load perturbation are shown in Tables 2 and 3, respectively.

When considering time delay, compare the system dynamics of the following three cases assuming the step load
TABLE 1: Simulation parameters of dynamic model of two-area interconnected AGC system.

\begin{tabular}{lcc}
\hline parameter & area 1 & area 2 \\
\hline$M_{i}$ & 11 & 12.5 \\
$D_{i}$ & 2.75 & 2.0 \\
$B_{i}$ & 28 & 19 \\
$R_{i}$ & 0.04 & 0.06 \\
$K_{\mathrm{r} i}$ & 0.3 & 0.4 \\
$T_{\mathrm{g} i}$ & 0.15 & 0.1 \\
$T_{\mathrm{ri}}$ & 11 & 9 \\
$T_{\mathrm{t} i}$ & 0.2 & 0.3 \\
$T_{12}$ & 0.85 & \\
\hline
\end{tabular}

TABLE 2: Parameters optimal solution under step signal.

\begin{tabular}{lc}
\hline parameter & optimal solution \\
\hline$m_{1}$ & 5.187793973963098 \\
$n_{1}$ & 4.591708935793283 \\
$q_{1}$ & 0.763401703669231 \\
$m_{2}$ & 5.107249768899896 \\
$n_{2}$ & 6.428451138599305 \\
$q_{2}$ & 0.579802457772249 \\
\hline
\end{tabular}

TABLE 3: Parameters optimal solution under random signal.

\begin{tabular}{lc}
\hline parameter & optimal solution \\
\hline$m_{1}$ & 4.496986082442389 \\
$n_{1}$ & 3.515193785989563 \\
$q_{1}$ & 2.588455740680591 \\
$m_{2}$ & 3.780302803800320 \\
$n_{2}$ & 0.197856439563561 \\
$q_{2}$ & 0.974260486543995 \\
\hline
\end{tabular}

perturbation $\Delta P_{\mathrm{L} 1}$ is $0.06 \mathrm{pu}$ and $\Delta P_{\mathrm{L} 2}$ is $0.01 \mathrm{pu}$ : (a) no processing for delay; (b) control sequence selection; and (c) control sequence selection with system compensation.

During the simulation, the output of the PV system is supposed from $0.2 \mathrm{pu}$ to $0.1 \mathrm{pu}$ at 20 seconds for the light intensity change and then returns to $0.2 \mathrm{pu}$ at 40 seconds in area 1 . The output of the PV system is supposed from $0.3 \mathrm{pu}$ to $0.1 \mathrm{pu}$ at 20 seconds for the light intensity change and then returns to $0.2 \mathrm{pu}$ at 40 seconds in area 2. The output response of the two areas is shown in Figure 7.

The results indicate that the system with compensation unit has better performance than the system without compensation and case $\mathrm{a}$ in which without the time delay 

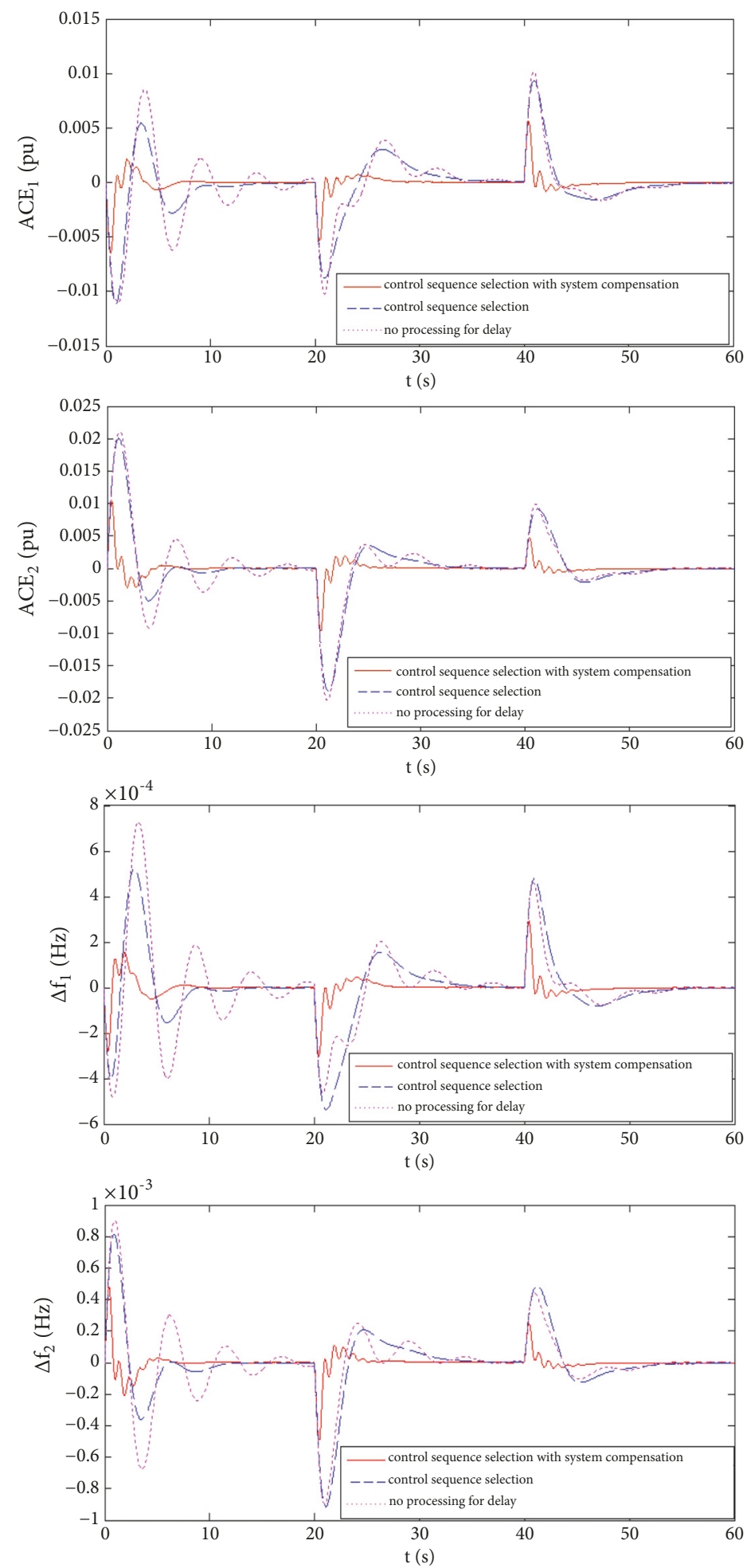

Figure 7: The step response curve of $\Delta f$. (a) Response of $\triangle A C E_{1}$. (b) Response of $\triangle A C E_{2}$. (c) Response of $\Delta f_{1}$. (d) Response of $\Delta f_{2}$.

processing has the worst performance in settling time and overshoot if time delay exists.

When the random load perturbations applied in the two areas are shown in Figure 8 and the output of the PV system is supposed from 0.2 pu to 0.1 pu at 240 seconds for the light intensity change and then returns to $0.2 \mathrm{pu}$ at 400 seconds in area 1, the output of the PV system is supposed from 0.3 pu to $0.1 \mathrm{pu}$ at 200 seconds for the light intensity change and then returns to $0.2 \mathrm{pu}$ at 400 seconds in area 2. The fluctuation of PV output and load perturbation may occur synchronously. The system dynamic responses of $\Delta f 1, \Delta f 2$ are shown in Figure 9. 

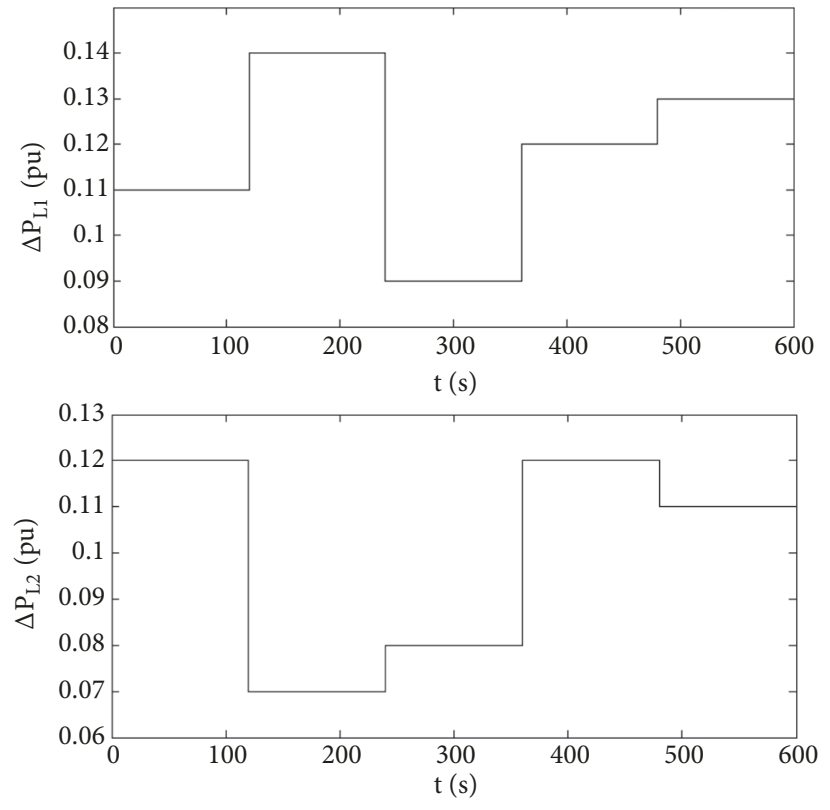

FIGURE 8: Random input signal. (a) $\Delta P_{\mathrm{L} 1}$; (b) $\Delta P_{\mathrm{L} 2}$.
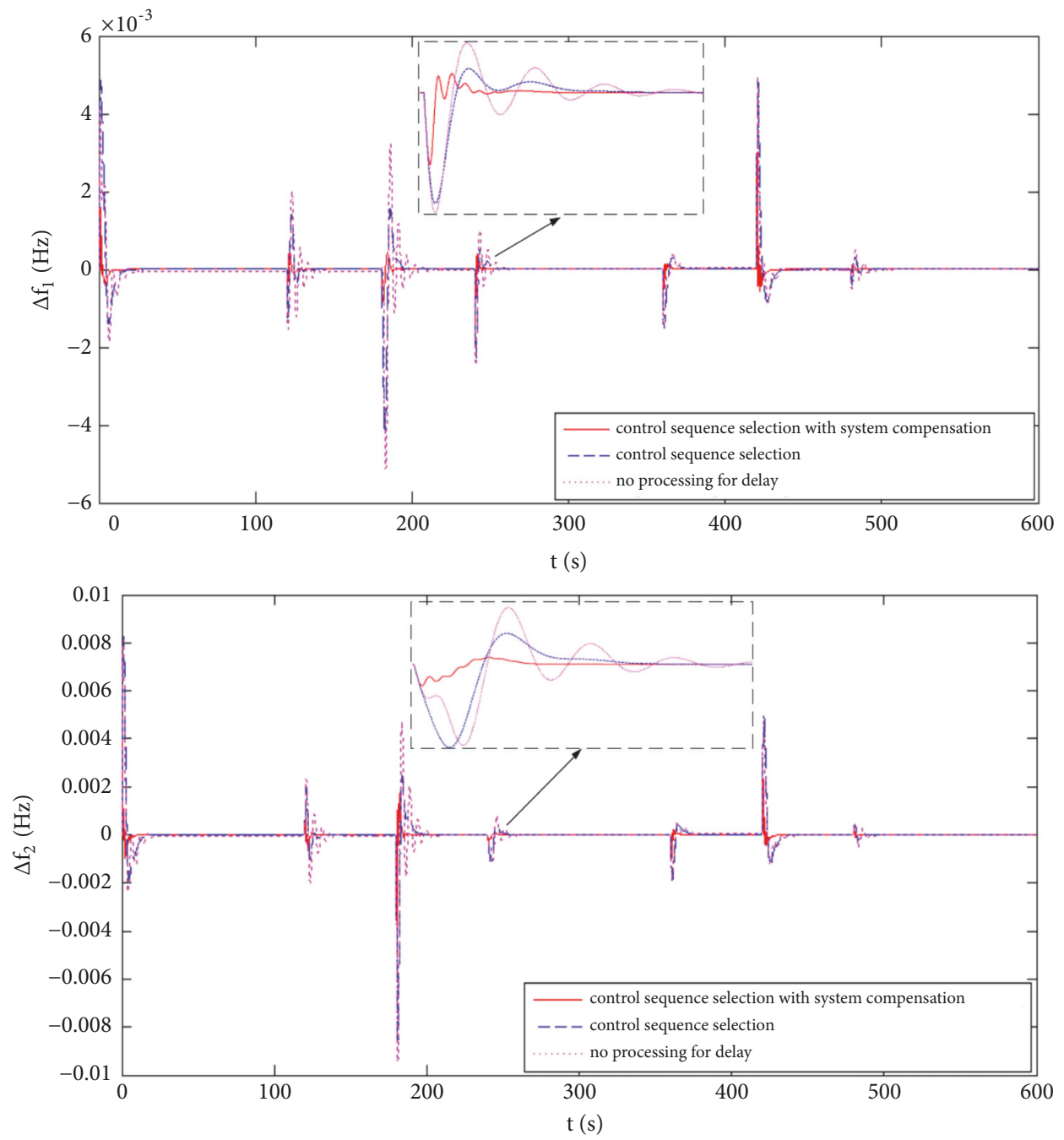

FIgURE 9: Response curve under random signal. (a) Response of $\Delta f_{1}$. (b) Response of $\Delta f_{2}$. 
Figure 9 reveals that when the fluctuation of PV output and load perturbation occurs synchronously at 240 seconds in area 1 , the influence of uncertainty will be enhanced. The proposed method still has the best control performance. Consequently, the research on the appropriate system compensation unit and method for the obtainment of control variable under time delay deserve to be concerned.

\section{Conclusion}

In this paper, a system compensation based model predictive AGC method is presented for the multiarea power systems with random time delay and penetration of PV system. A two-area connected power grid with PV systems is constructed. The construction of the system model takes into account the random time delay existing between different areas. According to the predictive characteristic of MPC, an improved method is proposed to mitigate the negative effects of the delay. The control variable is obtained through a selected method which depends on the predictive control sequence acquired from the latest received data when time delay exists. A compensation unit is designed to reduce the influence of uncertain fluctuation of load and PV output. The feasibility and effectiveness of the proposed method are verified not only on time delay processing, but also on the uncertainty treatment of the power output of the PV system.

\section{Data Availability}

The data used to support the findings of this study are available from the corresponding author upon request.

\section{Conflicts of Interest}

The authors declare that they have no conflicts of interest.

\section{Acknowledgments}

The research team members thank for the support by the National Natural Science Foundation of China (Grant no. 51309094).

\section{Supplementary Materials}

The supplementary material is the parameter matrix of twoarea interconnected power grid AGC dynamic model in Figure 2. (Supplementary Materials)

\section{References}

[1] A. Rahman, L. C. Saikia, and N. Sinha, "AGC of dish-Stirling solar thermal integrated thermal system with biogeography based optimised three degree of freedom PID controller," IET Renewable Power Generation, vol. 10, no. 8, pp. 1161-1170, 2016.

[2] S. Liu, P. X. Liu, and A. E. Saddik, "Modeling and stability analysis of automatic generation control over cognitive radio networks in smart grids," IEEE Transactions on Systems, Man, and Cybernetics: Systems, vol. 45, no. 2, pp. 223-234, 2015.

[3] H. Chavez, R. Baldick, and J. Matevosyan, "The Joint Adequacy of AGC and Primary Frequency Response in Single Balancing
Authority Systems," IEEE Transactions on Sustainable Energy, vol. 6, no. 3, pp. 959-966, 2015.

[4] L. C. Saikia, S. K. Das, P. Dash, and M. Raju, "Multi Area AGC with AC/DC Link and BES and Cuckoo Search Optimized PID Controller," in Proceedings of the 2015 3rd International Conference on Computer, Communication, Control and Information Technology (C3IT), pp. 1-6, Hooghly, India, Feburary 2015.

[5] R. K. Sahu, S. Panda, and U. K. Rout, "DE optimized parallel 2DOF PID controller for load frequency control of power system with governor dead-band nonlinearity," International Journal of Electrical Power \& Energy Systems, vol. 49, no. 1, pp. 19-33, 2013.

[6] P. K. Mohanty, B. K. Sahu, T. K. Pati, S. Panda, and S. K. Kar, "Design and analysis of fuzzy PID controller with derivative filter for AGC in multi-area interconnected power system," IET Generation, Transmission \& Distribution, vol. 10, no. 15, pp. 3764-3776, 2016.

[7] Y. Mi, Y. Fu, C. Wang, and P. Wang, "Decentralized sliding mode load frequency control for multi-area power systems," IEEE Transactions on Power Systems, vol. 28, no. 4, pp. 43014309, 2013.

[8] M. H. Khooban and T. Niknam, "A new intelligent online fuzzy tuning approach for multi-area load frequency control: self adaptive modified bat algorithm," International Journal of Electrical Power \& Energy Systems, vol. 71, pp. 254-261, 2015.

[9] E. Yao, V. W. S. Wong, and R. Schober, "Robust Frequency Regulation Capacity Scheduling Algorithm for Electric Vehicles," IEEE Transactions on Smart Grid, vol. 8, no. 2, pp. 984-997, 2017.

[10] L.-R. Chang-Chien, C.-C. Sun, and Y.-J. Yeh, "Modeling of wind farm participation in AGC," IEEE Transactions on Power Systems, vol. 29, no. 3, pp. 1204-1211, 2014.

[11] Y. Xu, F. Li, Z. Jin, and M. Hassani Variani, "Dynamic GainTuning Control (DGTC) Approach for AGC with Effects of Wind Power," IEEE Transactions on Power Systems, vol. 31, no. 5, pp. 3339-3948, 2016.

[12] A. Basit, A. D. Hansen, P. E. Sørensen, and G. Giannopoulos, "Real-time impact of power balancing on power system operation with large scale integration of wind power," Journal of Modern Power Systems and Clean Energy, vol. 5, no. 2, pp. 202210, 2017.

[13] A. Rahman, L. C. Saikia, and N. Sinha, "Automatic generation control of an interconnected two-area hybrid thermal system considering dish-stirling solar thermal and wind turbine system," Journal of Renewable Energy, vol. 105, pp. 41-54, 2017.

[14] T. H. Mohamed, H. Bevrani, A. A. Hassan, and T. Hiyama, "Decentralized model predictive based load frequency control in an interconnected power system," Energy Conversion and Management, vol. 52, no. 2, pp. 1208-1214, 2011.

[15] I. Pan and S. Das, "Fractional order AGC for distributed energy resources using robust optimization," IEEE Transactions on Smart Grid, vol. 7, no. 5, pp. 2175-2186, 2015.

[16] D. Apostolopoulou, P. W. Sauer, and A. D. Dominguez-Garcia, "Balancing authority area model and its application to the design of adaptive AGC systems," IEEE Transactions on Power Systems, vol. 31, no. 5, pp. 3756-3764, 2016.

[17] Y. Arya and N. Kumar, "BFOA-scaled fractional order fuzzy PID controller applied to AGC of multi-area multi-source electric power generating systems," Swarm and Evolutionary Computation, vol. 32, pp. 202-218, 2017.

[18] R. K. Sahu, S. Panda, and S. Padhan, "A hybrid firefly algorithm and pattern search technique for automatic generation control of multi area power systems," International Journal of Electrical Power \& Energy Systems, vol. 64, pp. 9-23, 2015. 
[19] Y. Arya, N. Kumar, and I. Nasiruddin, "AGCof a two-area multi-source power system interconnected via AC/DC parallel links under restructured power environment," Optimal Control Application \& Methods, vol. 37, no. 4, pp. 590-607, 2015.

[20] T. Yu, Y. M. Wang, W. J. Ye et al., "Stochastic optimal generation command dispatch based on improved hierarchical reinforcement learning approach," IET Generation, Transmission \& Distribution, vol. 5, no. 8, pp. 789-797, 2011.

[21] S. Sajadian and R. Ahmadi, "Model Predictive-Based Maximum Power Point Tracking for Grid-Tied Photovoltaic Applications Using a Z-Source Inverter," IEEE Transactions on Power Electronics, vol. 31, no. 11, pp. 7611-7620, 2016.

[22] F. Oldewurtel, A. Parisio, C. N. Jones et al., "Use of model predictive control and weather forecasts for energy efficient building climate control," Energy and Buildings, vol. 45, pp. 1527, 2012

[23] A. M. Ersdal, L. Imsland, and K. Uhlen, "Model Predictive Load-Frequency Control," IEEE Transactions on Power Systems, vol. 31, no. 1, pp. 777-785, 2016.

[24] H. Jiang, J. Lin, Y. Song et al., "Explicit model predictive control applications in power systems, ppAn AGC study for an isolated industrial system," IET Generation, Transmission \& Distribution, vol. 10, no. 4, pp. 964-971, 2016.

[25] Y.-S. Jang, J. Park, and Y. T. Yoon, "Designing structuredependent MPC-based AGC schemes considering network topology," Energies, vol. 8, no. 5, pp. 3437-3454, 2015.

[26] M. G. Villalva, J. R. Gazoli, and E. R. Filho, "Comprehensive approach to modeling and simulation of photovoltaic arrays," IEEE Transactions on Power Electronics, vol. 24, no. 5, pp. 11981208, 2009.

[27] Y. Shi and B. Yu, "Robust mixed $H_{2} / H_{\infty}$ control of networked control systems with random time delays in both forward and backward communication links," Automatica, vol. 47, no. 4, pp. 754-760, 2011. 


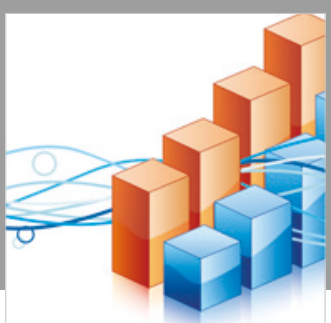

Advances in

Operations Research

\section{-n-m}
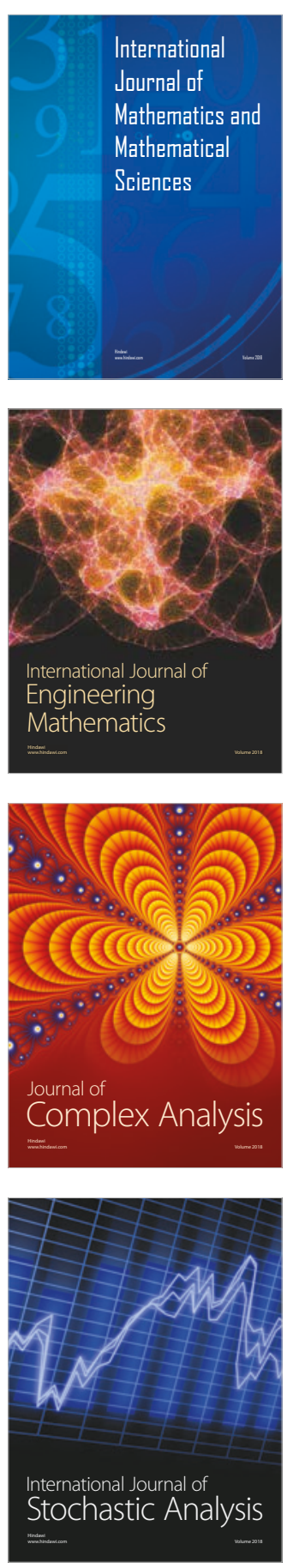
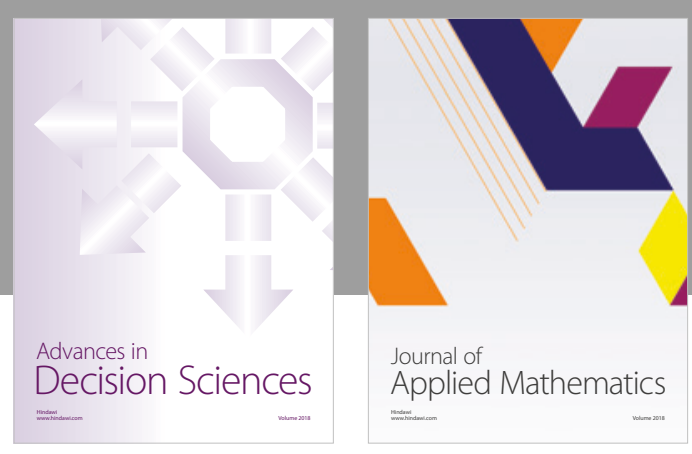

Journal of

Applied Mathematics
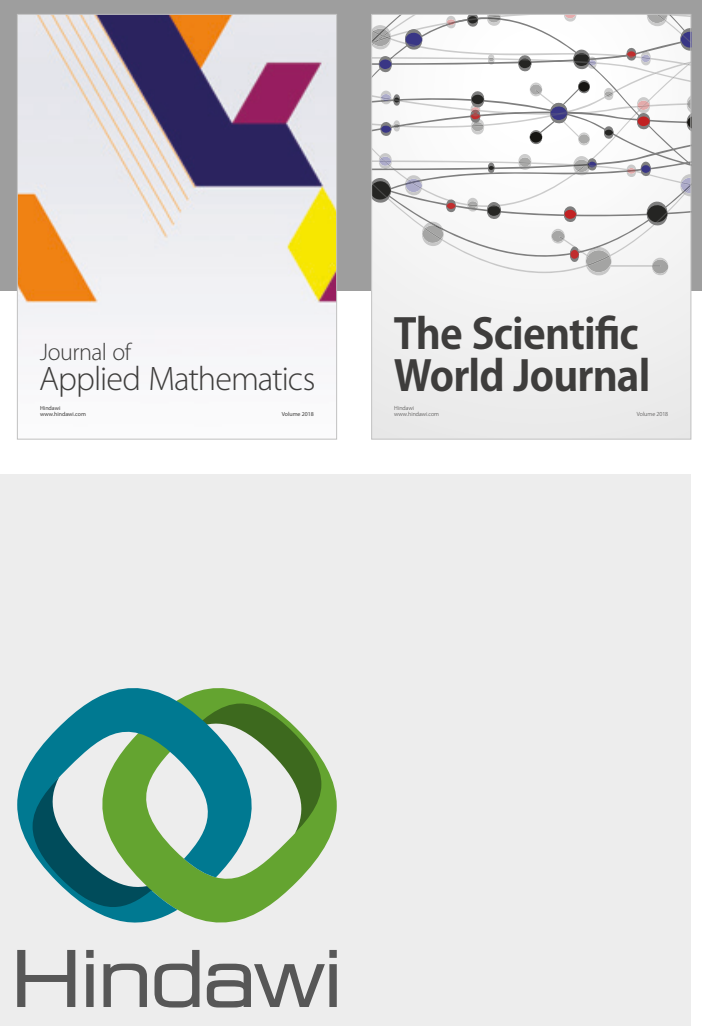

Submit your manuscripts at

www.hindawi.com

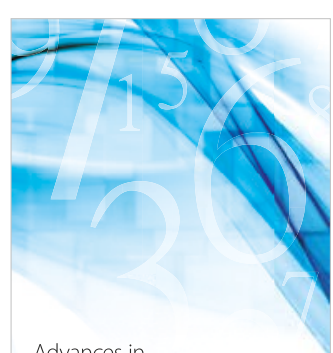

Advances in
Numerical Analysis
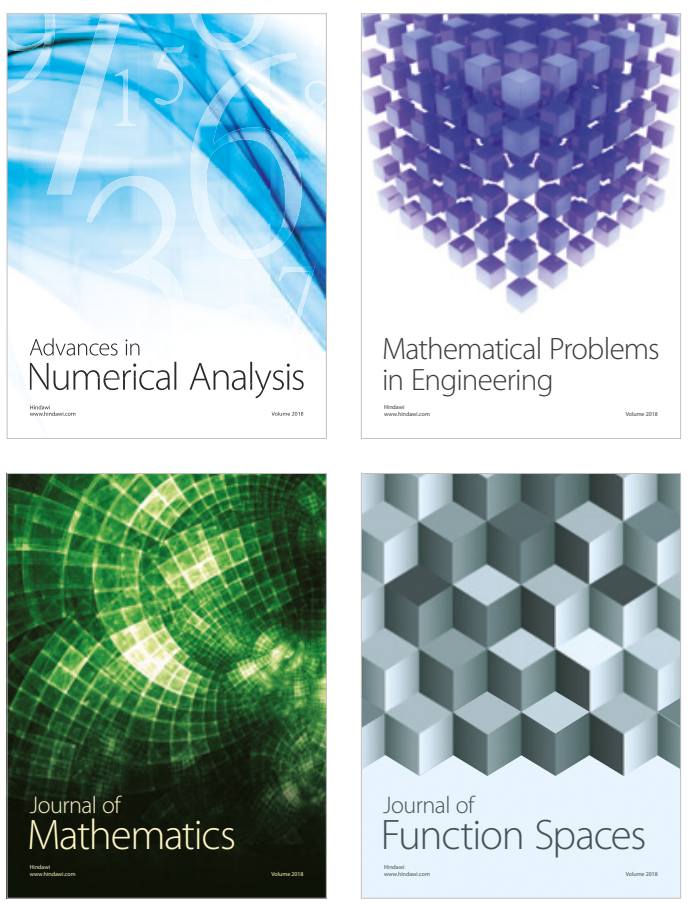

Mathematical Problems in Engineering

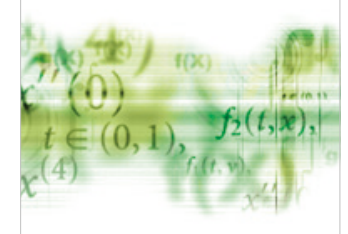

International Journal of

Differential Equations

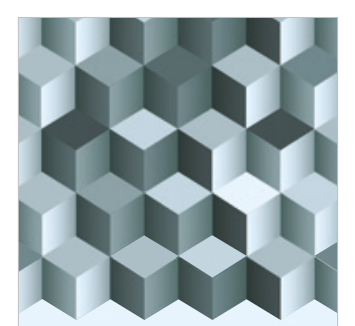

Journal of

Function Spaces
The Scientific

World Journal

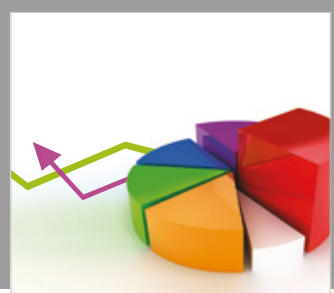

Journal of

Probability and Statistics
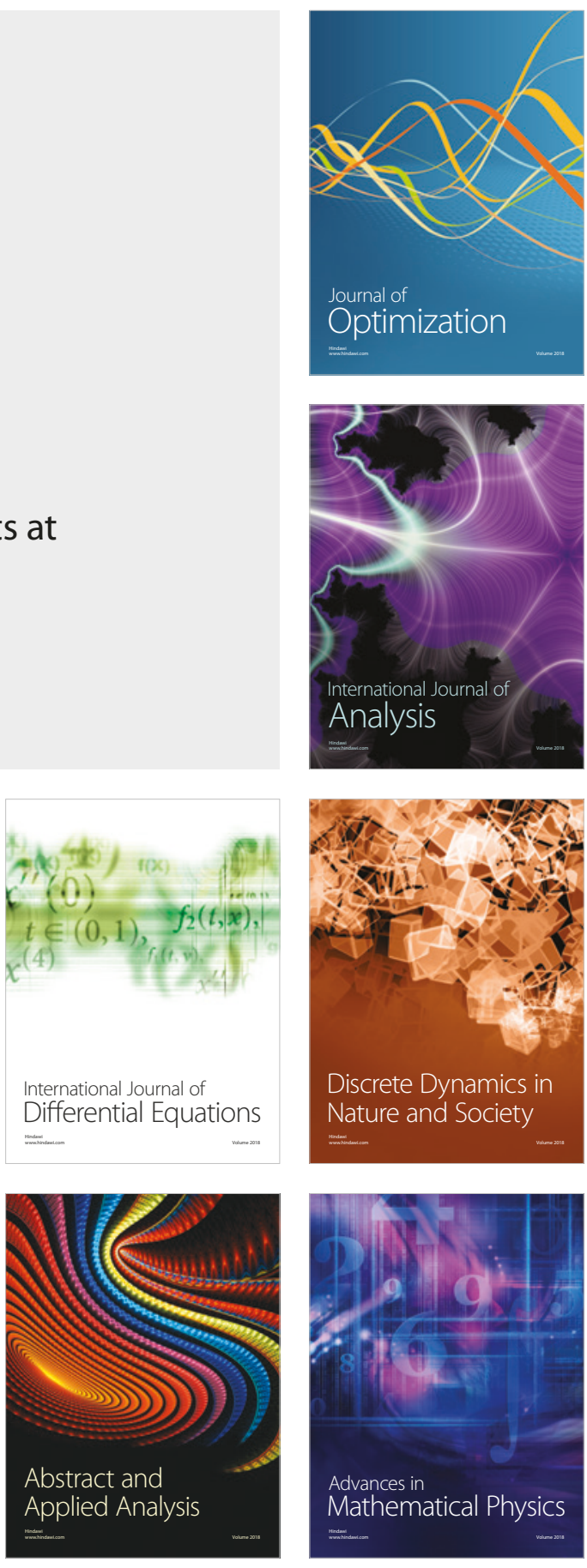